\title{
The Dynamic Impact of Macroeconomic News on Long-Term Inflation Expectations
}

Michael Hachula

Dieter Nautz

School of Business \& Economics

Discussion Paper

Economics

$2017 / 12$ 


\title{
The Dynamic Impact of Macroeconomic News
}

\section{on Long-Term Inflation Expectations*}

\author{
Michael Hachula ${ }^{1,2} \quad$ Dieter Nautz ${ }^{2}$
}

May 16, 2017

\begin{abstract}
Well-anchored inflation expectations should not react to short-term oriented macroeconomic news. This paper analyzes the dynamic response of inflation expectations to macro news shocks in a structural VAR model. As identification of structural macro news shocks is controversial, we use a proxy SVAR model where, by construction, unobservable macro news shocks correlate with observable surprises from macroeconomic news announcements. Our results confirm that macro news shocks have no impact on U.S. long-term inflation expectations in the long run. In the short run, however, the degree of expectations de-anchoring is non-negligible.
\end{abstract}

JEL-Classification: E31, E52, C32.

Keywords: Dynamics of Inflation Expectations, Expectations Anchoring, Macroeconomic News, proxy SVAR.

\footnotetext{
*We are thankful to Benjamin Beckers, Till Strohsal, Mathias Trabandt, Lars Winkelmann, and seminar participants at Freie Universität Berlin and at University of Hamburg for very helpful comments and suggestions. ${ }^{1}$ German Institute for Economic Research (DIW Berlin).

${ }^{2}$ Freie Universität Berlin, Department of Economics.
} 


\section{Introduction}

Central banks increasingly explain their decisions with the need to keep inflation expectations well anchored. While there is a general agreement that well-anchored long-term inflation expectations should not respond to short-term oriented macroeconomic news, it is not obvious how to implement this anchoring criterion empirically. Following Gürkaynak et al. (2010b), the predominant part of the literature regresses long-term inflation expectations on the surprise component contained in macroeconomic news announcements (MNAs). In accordance with e.g. Bauer (2015) and Nautz and Strohsal (2015), a significant reaction of expectations to MNA surprises implies de-anchored expectations and a lack of central bank credibility. This part of the literature restricts the attention to the instantaneous response of inflation expectations to MNA surprises. Thus, it cannot account for the complex dynamics of inflation expectations. In particular, if the effect of news on expectations is very persistent, the de-anchoring problem might be more severe than the immediate response of expectations seems to suggest.

A second strand of the literature builds on the fact that short-term inflation expectations react much stronger to macro news than longer-term expectations. Therefore, following Jochmann et al. (2010), spill-overs from short- to long-term expectations are seen as a sign of de-anchoring, see e.g. Ehrmann (2015) and Strohsal et al. (2016). Although these contributions use short-term inflation expectations as a variable summarizing macro news shocks, they do not account for the information content of observable MNA surprises. Nautz et al. (2017), for example, use a structural VAR model for short- and long-term inflation expectations to analyze the de-anchoring of U.S. inflation expectations stirred by macro news shocks. The unobservable macro news shocks are identified by restricting their long-run impact on long-term inflation expectations to be zero. This identification strategy has two important drawbacks. First, the identifying long-run restriction implies the possibly controversial assumption that expectations are completely anchored in the long run. Second, the estimated macro news shocks may only be loosely connected to actual news about shortrun economic developments. However, a weak link of estimated shocks with observable 
information, like MNA surprises, severely undermines the credibility of the identification strategy and, thus, of the whole empirical analysis.

This paper tries to bridge the gap between both strands of the empirical literature. To that aim, we use MNA surprises as proxy variables to identify unobservable macro news shocks in a structural VAR framework (see Stock and Watson, 2012, Mertens and Ravn, 2013). Using a proxy SVAR allows us to investigate the dynamic impact of macro news shocks on U.S. inflation expectations, where the identified shocks correlate with observable information on short-run economic developments by construction. Moreover, since no longrun restriction has to be imposed, our results are not based on the a priori assumption that inflation expectations are anchored in the long run.

Our empirical results indicate a non-negligible degree of short-run de-anchoring of U.S. inflation expectations. Macro news shocks have a significant impact on long-term inflation expectations for up to 50 trading days. The response, however, fades out eventually, confirming that expectations are anchored in the longer run. In the following section, we describe the proxy SVAR model and our identification strategy. Section 3 presents the empirical results for U.S. inflation expectations, and Section 4 concludes.

\section{The Identification of Macro News Shocks in a Proxy SVAR}

Following Nautz et al. (2017), the starting point of our analysis is a reduced-form VAR model for short- and long-term inflation expectations:

$$
\left(\begin{array}{c}
\pi_{s, t}^{e} \\
\pi_{l, t}^{e}
\end{array}\right)=c+\Pi(L)\left(\begin{array}{c}
\pi_{s, t-1}^{e} \\
\pi_{l, t-1}^{e}
\end{array}\right)+\left(\begin{array}{l}
u_{s, t} \\
u_{l, t}
\end{array}\right) .
$$

$c$ is a vector of constants, the matrix $\Pi(L)$ in lag polynomials captures the autoregressive part of the model, and $u_{s, t}$ and $u_{l, t}$ are reduced-form shocks with covariance matrix $\Sigma_{u}$. Reduced-form models are not informative about the various economic forces that can move inflation expectations away from their anchor. Therefore, we aim to identify structural 
macro news shocks that should reflect all new information about short-run economic developments that have no implications for the long run. Accordingly, these shocks should have a significant impact on short-term inflation expectations, while they should not affect firmly anchored long-term inflation expectations.

In the following, we show how the proxy SVAR approach developed by Stock and Watson (2012) and Mertens and Ravn (2013) can be used to identify structural macro news shocks. Suppose that the two reduced-form innovations $u_{t}$ of the VAR are related to two structural shocks, the macro news shock $\varepsilon_{t}^{\text {news }}$ and a second shock $\varepsilon_{t}^{*}$, as follows:

$$
u_{t}=b^{n e w s} \varepsilon_{t}^{n e w s}+b^{*} \varepsilon_{t}^{*}
$$

The $2 \times 1$ vector $b^{\text {news }}$ captures the impact impulse vector to a macro news shock. Note that $\varepsilon_{t}^{*}$ is uncorrelated with the macro news shock and, thus, plays no role for the assessment of expectations anchoring. It can be left unidentified in the proxy SVAR ${ }^{1}$

Identification of the macro news shock in the proxy VAR exploits its correlation with a set of proxy variables (or external instruments) $m_{t}$, whereas the proxies need to be uncorrelated with the other structural shock:

$$
\begin{gathered}
E\left(m_{t} \varepsilon_{t}^{n e w s}\right)=\phi \neq 0, \\
E\left(m_{t} \varepsilon_{t}^{*}\right)=0 .
\end{gathered}
$$

Under these conditions, the relative responses of the variables in the system to a macro news shock, $b_{\text {long }}^{\text {news }} / b_{\text {short }}^{\text {news }}$, can be consistently estimated using the correlation between $m_{t}$ and the estimated reduced-form residuals. Note that this relative response allows to compute the response of long-term expectations to a macro news shock that affects short-term inflation expectations by a pre-scaled amount on impact. Additionally assuming that $\Sigma_{\varepsilon}=I$, Mertens and Ravn (2013) show how to then fully retrieve $b^{\text {news }}$.

In our application, the proxy variables $m_{t}$ are a set of MNA surprises. Following Gertler

${ }^{1}$ While macro news shocks are short-term oriented, the second shock may refer to all long-run economic developments, including news about the central bank's long-run inflation target, see Nautz et al.|(2017). 
and Karadi (2015) and Cesa-Bianchi et al. (2015), the proxy SVAR is implemented using a two stage least squares approach. In the first stage, the estimated series of reduced-form shocks for short-term inflation expectations, $u_{t}^{s}$, is regressed on the set of proxy variables $m_{t}$ :

$$
u_{t}^{s}=\tau m_{t}+\eta_{1 t}
$$

This yields the fitted values $\hat{u}_{t}{ }^{s}=\hat{\tau} m_{t}$ which capture the variation in $u_{t}^{s}$ due to the proxy variables and, thus, due to the macro news shocks. In the second stage regression,

$$
u_{t}^{l}=\gamma \hat{u}_{t}^{s}+\eta_{2 t}
$$

$\hat{\gamma}$ is a consistent estimate of $b_{\text {long }}^{\text {news }} / b_{\text {short }}^{\text {news }}$, see Gertler and Karadi (2015).

\section{Data and Empirical Results}

\subsection{Inflation expectations}

Our empirical analysis is based on inflation expectations derived from daily data for inflationlinked treasury securities. Expectations are measured by break-even inflation (BEI) rates, i.e. the difference between yields of nominal and inflation-indexed treasury bonds with the same maturity. BEI rates are taken from the database provided by the Federal Reserve Board staff (see Gürkaynak et al., 2010a). As a measure of short-term expectations we employ the three year spot BEI rate. For long-term inflation expectations, we use the five year forward BEI rate five years ahead, as this forward maturity is predominantly used as an indicator by central banks and in the empirical literature. The sample period begins in July 2009 and runs until August 2016. We start in 2009 to avoid distortions of the expectations measures caused by market turbulences during the financial crisis. It is important to note that our results are robust regarding the employed measures and adjustments for liquidity and risk. ${ }^{2}$

\footnotetext{
${ }^{2}$ The Appendix contains a comprehensive robustness and sensitivity analysis. It shows that the main results are robust to using BEI rates with alternative maturities (e.g. one year forward nine years ahead), adjusting the data with different regression based approach for liquidity and financial market risk, or using inflation
} 
The development of short- and long-term inflation expectations is displayed in Figure 1.

Figure 1 Inflation expectations in the U.S.

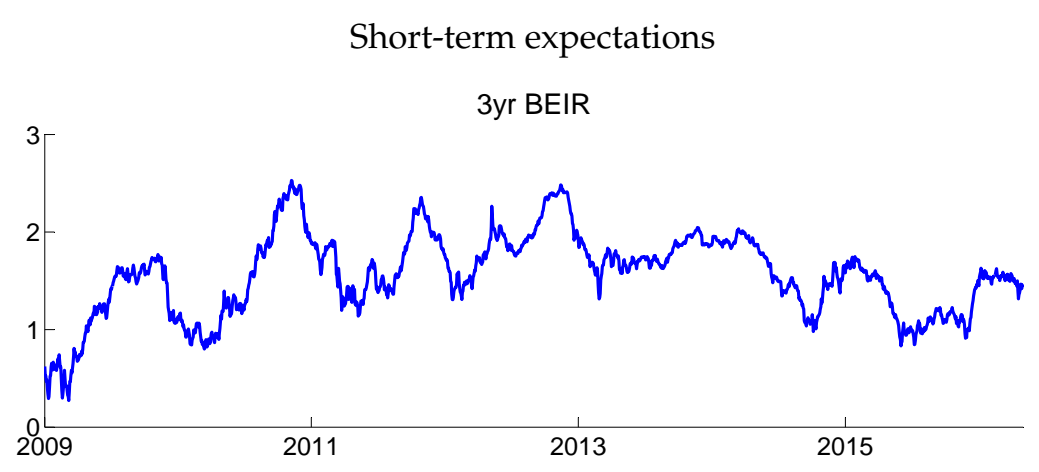

Long-term expectations

5yr5yr forward BEIR

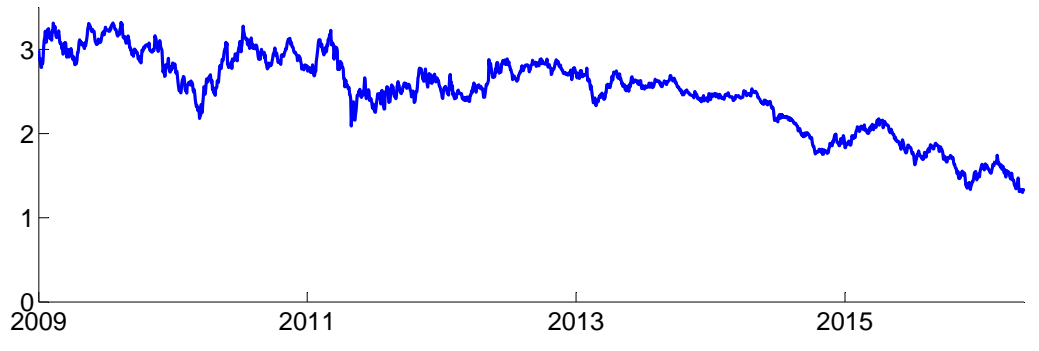

Note: The figure shows the inflation expectations measures used in the baseline estimation. The short-term measure is the three year spot break-even inflation rate (3yr BEIR), the long-term measure is the break-even inflation rate over five years in five years (5yr5yr forward BEIR). The sample is 07/01/2009- 08/26/2016.

\subsection{MNA surprises}

MNA surprises are natural candidates for the proxy variables $m_{t}$ to identify the unobservable macro news shocks, since they capture the difference between the actual realization of a macroeconomic variable and its expected value. We collect 33 MNAs from Bloomberg, covering the lion's share of available MNAs and including all important ones. The complete list can be found in Table 3 in the Appendix. For each variable, we obtain the actual data release and the expected realization taken from a survey of economists. MNA surprises are

swap data instead of BEI rates to capture expectations. Also, the results are qualitatively robust to estimating the model based on a sample period with only data from before the financial crisis. 
the difference between the two. The resulting series are standardized prior to the estimation to make them comparable. Most of the MNA series realize once a month, with a few exceptions that are realized quarterly, like GDP growth, or weekly, like initial jobless claims.

\subsection{Identification of macro news shocks}

For the proxy SVAR approach to work, conditions (3a) and (3b) need to be fulfilled. While these conditions are not directly testable as the structural shocks are unobserved, one can test whether there is a sufficiently strong correlation between the proxies and the reducedform VAR innovations. In line with e.g. Gertler and Karadi (2015), this is a prerequisite for the proxies not being a weak instrument, but a relevant one that is sufficiently correlated with the structural shock of interest.

Therefore, our empirical application proceeds as follow. First, we estimate the reducedform VAR for short- and long-term inflation expectations to obtain the reduced-form shocks, $\hat{u}_{t}^{s}$ and $\left.\hat{u}_{t}^{l}\right]^{3}$ Then, in order to avoid a weak instrument problem, we maximize the correlation (F-statistic) between the set of proxy variables and $\hat{u}_{t}{ }^{s}$. Following a general to specific approach, we obtain an optimal set of proxies that contains surprises related to the consumer price index, industrial production, initial jobless claims, the conference board leading economic index, and non-farm payrolls. The results from the first stage identification regression are presented in Table 1. Interestingly, the R-square is of the same order of magnitude usually found in news regressions. Notice further that the resulting F-statistic (11.98) is well above the recommended value of ten usually required for relevant instruments in the identification approach.

\subsection{The response of long-term inflation expectations to macro news shocks}

Having identified the structural macro news shocks with the proxy variables, we now evaluate the dynamic impact of the shocks on U.S. inflation expectations. Figure 2 displays the

\footnotetext{
${ }^{3}$ According to standard information criteria, we choose a lag length of four. Note, however, that our main results do not depend on this choice.
} 
Table 1 Results from first stage identification regression

\begin{tabular}{lccccc}
\hline \hline \multicolumn{6}{c}{ First stage equation: $u_{t}^{s}=\tau_{i} M N A_{i t}+\eta_{1 t}$} \\
\hline & \multicolumn{4}{c}{$\tau_{i}$} \\
& cons. price & industrial & init. jobless & conf. board & non-farm \\
index & production & claims & lead. index & payrolls \\
\hline$u_{t}^{s}$ & $0.038^{* * *}$ & $-0.010^{* *}$ & $-0.005^{* * *}$ & $-0.012^{* *}$ & $0.017^{* * *}$ \\
& $(5.61)$ & $(-2.13)$ & $(-2.77)$ & $(-2.14)$ & $(3.54)$ \\
\hline F-stat: 11.98 & Observations: 1833 & $R^{2}: 0.03$ & & & \\
\hline \hline
\end{tabular}

Note: The table shows results from the first stage identification regression, where the reduced-form residuals of short-term inflation expectations are regressed on the set of proxy variables. ${ }^{* * *},{ }^{* *},{ }^{*}$ denote significance at the $1 \%, 5 \%, 10 \%$ levels. $t$-statistics are given below estimates.

impulse response of long-term inflation expectations to a unit macro news shock, along with 90\% confidence bands. Following Mertens and Ravn (2013) and Gertler and Karadi (2015), for statistical interference a fixed-design wild bootstrap procedure is applied that accounts for estimation uncertainty in both stages of the structural VAR estimation: reduced-form estimation and identification regressions. Since the bootstrap takes both sources of uncertainty into account, confidence bands in proxy SVAR models are expected to be relatively wide. Yet, in our application, the response of long-term expectations stays significantly positive for about 50 trading days. Therefore, the impact of macro news shocks on long-term expectations is far from negligible in the short run. In the long run, however, the response fades out and expectations return to their pre-shock level eventually. In accordance with Nautz et al. (2017), this indicates that inflation expectations are anchored in long run.

Figure 2 The impulse response of long-term inflation expectations to a macro news shock 5yr5yr forward BEIR

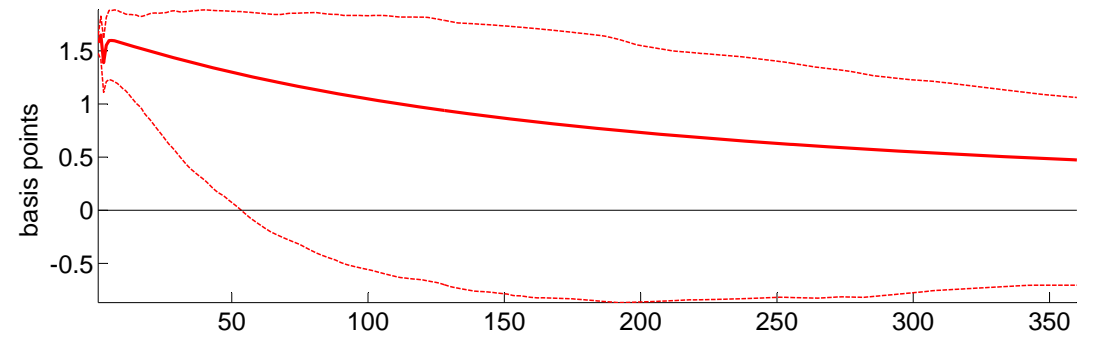

Note: Impulse responses, along with their $90 \%$ confidence bands based on 500 bootstrap replications, of long-term inflation expectations to a unit macro news shock. Sample: 07/01/2009 - 08/26/2016.

Forecast error variance decompositions can be used to further evaluate the importance of 
macro news shocks for the variance of long-term inflation expectations and, thus, the degree of short-run de-anchoring $4^{4}$ According to Table 2 the influence of macro news shocks on the forecast error variance of long-term inflation expectations is substantial. In the short run, the fraction of variance explained by the shock is $16 \%$, while over time this slightly declines to $11 \%$. This indicates that even though expectations are anchored in the long run, they are still considerably influenced by macro news shocks.

Table 2 Contribution of macro news shocks to variance of long-term inflation expectations

\begin{tabular}{c|cccccccc}
\hline \hline & \multicolumn{8}{|c}{ Horizon in days } \\
variable & 1 & 5 & 10 & 20 & 30 & 90 & 150 & 360 \\
\hline$\pi_{l}^{e}$ & 16 & 16 & 16 & 16 & 16 & 14 & 13 & 11 \\
\hline \hline
\end{tabular}

Note: Forecast error variance decomposition of long-term inflation expectations $\pi_{l}^{e}$ from the SVAR model with respect to the macroeconomic news shock.

\section{Conclusion}

This paper proposes a proxy SVAR model as a tool to analyze the impact of macro news shocks on inflation expectations. Using MNA surprises as proxy variables for unobservable structural macro news shocks has two major advantages. First, the proxy SVAR does not a priori assume inflation expectations to be anchored in the long run. Second, the economic interpretation of the empirical results is not controversial because the identified macro news shocks are correlated with MNA surprises by construction. While macro news shocks are found to be a significant source of short-run distortions, our results confirm that U.S. inflation expectations are anchored in the long run.

\footnotetext{
${ }^{4}$ For a detailed explanation on how to exploit $b^{\text {news }}$ and the covariance restrictions to derive the row of the inverse impact matrix $B^{-1}$ corresponding to $\varepsilon_{t}^{\text {news }}$, see e.g. de Wind (2014).
} 


\section{References}

Autrup, S.L. and M. Grothe (2014): Economic surprises and inflation expectations: Has anchoring of expectations survived the crisis?, Working Paper Series No. 1671, European Central Bank.

Bauer, M.D. (2015): Inflation Expectations and the News, International Journal of Central Banking, 11(2), 1-40.

Cesa-Bianchi, A., L.F. Cespedes and A. Rrebucci (2015): Global Liquidity, House Prices, and the Macroeconomy: Evidence from Advanced and Emerging Economies, Journal of Money, Credit and Banking, 47(S1), 301-335.

Christensen, J.H.E. and J.M. Gillan (2012): Do Fed TIPS purchases affect market liquidity?, FRBSF Economic Letter (mar5).

de Wind, J. (2014): Time variation in the dynamic effects of unanticipated changes in tax policy, CPB Discussion Paper No. 271, CPB Netherlands Bureau for Economic Policy Analysis.

Ehrmann, M. (2015): Targeting Inflation from Below: How Do Inflation Expectations Behave?, International Journal of Central Banking, 11(4), 213-249.

Galati, G., S. Poelhekke and C. Zhou (2011): Did the Crisis Affect Inflation Expectations?, International Journal of Central Banking, 7(1), 167-207.

Gertler, M. and P. Karadi (2015): Monetary Policy Surprises, Credit Costs, and Economic Activity, American Economic Journal: Macroeconomics, 7(1), 44-76.

Gürkaynak, R.S., A. Levin and E. Swanson (2010b): Does Inflation Targeting Anchor LongRun Inflation Expectations? Evidence from the U.S., UK, and Sweden, Journal of the European Economic Association, 8(6), 1208-1242.

Gürkaynak, R.S., B. Sack and J.H. Wright (2010a): The TIPS Yield Curve and Inflation Compensation, American Economic Journal: Macroeconomics, 2(1), 70-92.

Jochmann, M., G. Koop and S.M. Potter (2010): Modeling the dynamics of inflation compensation, Journal of Empirical Finance, 17(1), 157-167.

Mertens, K. and M.O. Ravn (2013): The dynamic effects of personal and corporate income tax changes in the United States, The American Economic Review, 103(4), 1212-1247.

Nautz, D., A. Netsunajev and T. Strohsal (2017): The Anchoring of Inflation Expectations in the Short and in the Long Run, Macroeconomic Dynamics, forthcoming.

Nautz, D., L. Pagenhardt and T. Strohsal (2017): The (De-)Anchoring of Inflation Expectations: New Evidence from the Euro Area, North American Journal of Economics and Finance (40), 103-115.

Nautz, D. and T. Strohsal (2015): Are US inflation expectations re-anchored?, Economics Letters, 127(C), 6-9. 
Netsunajev, A. and L. Winkelmann (2016): International dynamics of inflation expectations, SFB 649 Discussion Papers No. SFB649DP2016-019, Sonderforschungsbereich 649, Humboldt University, Berlin, Germany.

Stock, J.H. and M.W. Watson (2012): Disentangling the Channels of the 2007-09 Recession, Brookings Papers on Economic Activity, 44(1 (Spring), 81-156.

Strohsal, T., R. Melnick and D. Nautz (2016): The time-varying degree of inflation expectations anchoring, Journal of Macroeconomics, 48, $62-71$. 


\section{Appendix}

\section{A. Data and sources}

Table 3 Economic data releases (MNAs)

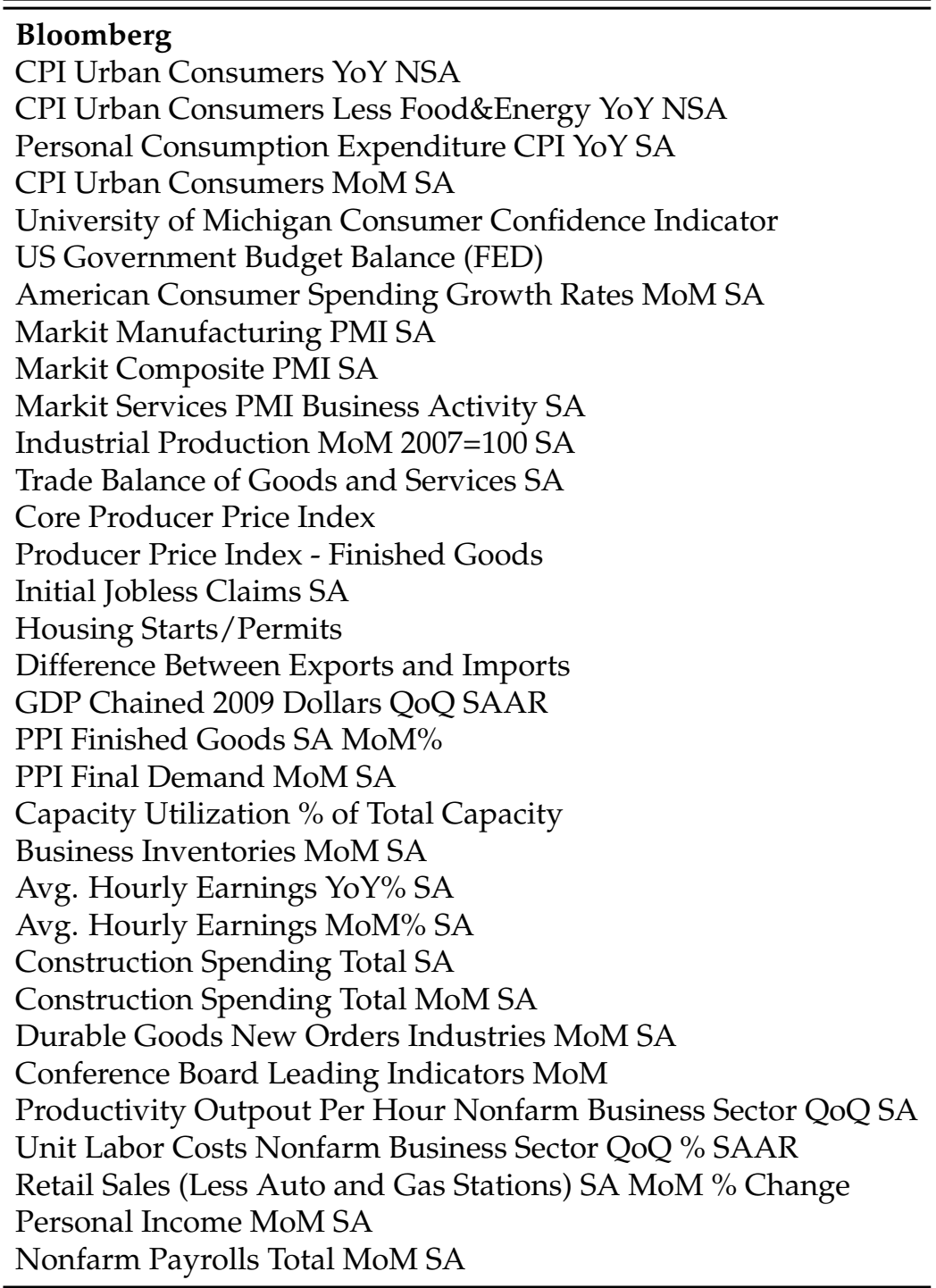


Table 4 Data construction and sources

\begin{tabular}{|c|c|}
\hline Variable & Construction and source \\
\hline Break-even inflation rates & $\begin{array}{l}\text { Source: Federal Reserve Board. Initially constructed by } \\
\begin{array}{l}\text { Gürkaynak et al. (2010b). Link to WP with latest data update: } \\
\text { https://www.federalreserve.gov/econresdata/feds/2008/index.htm. }\end{array}\end{array}$ \\
\hline MNAs & Source: Bloomberg. 33 series, see Table 3 \\
\hline Inflation swap rates & $\begin{array}{l}\text { End-of-day rates on US zero-coupon inflation swaps. } \\
\text { Bloomberg. }\end{array}$ \\
\hline $\begin{array}{l}\text { Relative trading vol- } \\
\text { ume of inflation-indexed } \\
\text { bonds }\end{array}$ & $\begin{array}{l}\text { Trading volume of inflation-indexed treasury bonds divided by trading } \\
\text { volume of nominal treasury bonds. Source: Federal Reserve Bank of } \\
\text { New York. The trading volume is published about once a week. We set } \\
\text { all days with no observation equal to the last observed relative volume. }\end{array}$ \\
\hline VIX & $\begin{array}{l}\text { Option-implied volatility index. Source: Chicago Board Options Ex- } \\
\text { change, retrieved from St. Louis FRED. }\end{array}$ \\
\hline Corporate bond spread & $\begin{array}{l}\text { Spread between AAA-rated corporate bond yields and nominal gov- } \\
\text { ernment bond yields. Source: Bloomberg, own calculations. }\end{array}$ \\
\hline
\end{tabular}




\section{B. Sensitivity and robustness analysis}

\section{B.1. Alternative measures of short-term and long-term expectations}

In this appendix, we evaluate the sensitivity of the main results to various modifications in the specification. First, we assess whether results are robust to the specific definition of short-term expectations. For this, the model is re-estimated replacing the three year spot BEI rate by the two and four year spot BEI rate, respectively. The response of long-term expectations to the macro news shock and, thus, results regarding the anchoring of expectations are basically unchanged by this alteration (see Figure 4 in the Appendix).

Then, we also re-estimate the model using a different measure of long-term inflation expectations. Specifically, we replace the five year five year forward BEI rate from the baseline specification by the one year nine year forward BEI rate, the inflation expectations over one year in nine years. While the five year five year forward is often used in the anchoring literature and central banks closely monitor it, the rate might still entail some business cycle component that potentially influences its reaction to the macro news shock. Therefore, as a sensitivity check, we use a rate that solely covers a period even further into the future. An impulse response for the corresponding model can be found in Appendix C. Figure 5 panel a). The effects of macro news shocks on long-term expectations are found to be very similar to the baseline specification.

\section{B.2. Inflation swap rates instead of $B E I$ rates}

Next, we assess the sensitivity of the results to generally using break-even inflation rates from treasury bonds as financial market based measures of expectations, since break-even rates potentially include a distorting liquidity premium. Therefore, we re-estimate the bivariate model replacing the BEI rates by expectation measures based on inflation swaps following Bauer (2015) 5 While swap rates also include a liquidity premium, the premium

\footnotetext{
${ }^{5}$ Inflation swaps are financial arrangements in which one party pays the CPI inflation rate on an underlying notional amount while the other party pays a fixed interest rate on the same notional. Specifically, we use
} 
is not necessarily connected to the one in BEI rates. Therefore, using them is a useful exercise to evaluate the sensitivity of the main results. Specifically, we use swap rates with the same maturities as in the baseline model. The results from the model with swap data can be found in Appendix $\mathrm{C}$ in Figure 5 panel b). The impulse response shows a reaction of long-term inflation expectations to the macro news shock that is very similar to the one in the baseline specification, but with the response fading out slightly later.

\section{B.3. Liquidity adjustment for BEI rates}

We also evaluate the sensitivity of the estimates by following an approach that is often used in the literature to deal with the issue of liquidity premia: pre-filtering BEI rates by regressing them on measures of liquidity risk. For this purpose, different measures of liquidity risks are brought forward. We use two approaches based on the relative trading volume on inflation-indexed treasury bond markets (see Gürkaynak et al., 2010b, Bauer, 2015, Nautz and Strohsal, 2015) and the implied stock market volatility (VIX) (see Galati et al., 2011, Christensen and Gillan, 2012, Nautz et al., 2017, Netsunajev and Winkelmann, 2016), respectively ${ }^{6}$ The results using the pre-filtered data can be found in Appendix C in Figure 5 panels c) and d). The impulse response of VIX-pre-filtered long-term expectations to the macro news shock is very similar to the one with the unfiltered baseline data. Filtering with market volume, on the other hand, yields a more persistent response that nevertheless also fades out eventually.

data on end-of-day rates of U.S. zero-coupon inflation swaps from Bloomberg. Zero-coupon means that no payments are received until the settlement date of the arrangement. The data is available for maturities from two to ten years, so that we can use the three year swap rate and construct a five year five year forward swap rate as for the BEI rates in the baseline specification.

${ }^{6}$ We do not use the pre-filtered BEI rates in the baseline specification for several reasons. First, the filtered rates from the two approaches differ considerably and it is not a priori clear which one to prefer. Second, the prefiltering regressions are very sensitive to the specification of the sample. Therefore, results from a pre-crisis estimation as carried out in Section B.4 would have been difficult to compare to the baseline model. Similarly, also a robustness check with inflation swap data would not have a straightforward interpretation. Third, prefiltering the data with a regression based approach potentially induces a generated regressor problem that is difficult to correct for in the context of the SVAR model. 


\section{B.4. Inflation anchoring before and after the financial crisis}

Lastly, we investigate the role of sample selection in shaping the main results. Recall that the baseline sample comprises only the post-crisis period starting in 2009. We carry out an additional estimation of the baseline model with only pre-crisis data to assess how this affects our main results with the proxy variables SVAR approach. In particular, we use a sample that starts in 2004, once the inflation-indexed bond markets were out of infancy (see, for example, Bauer, 2015), and ends with the bankruptcy of Lehman brothers in September 2008 7 The corresponding impulse response of long-term inflation expectation to the macro news shock is shown in Figure 3 in Appendix C. The impact effect of the macro news shock is only about half as large and fades out in about half the time as in the post-crisis sample 8 The difference in inflation anchoring between sample periods is also reflected in the forecast error variance decompositions. The corresponding decomposition for the pre-crisis sample (see Table 5 in Appendix D) shows that macro news shocks contribute only half as much to the variance of long-term expectations as found for the post-crisis baseline. Thus, the dynamic SVAR approach indicates a stronger de-anchoring of inflation expectations with respect to macroeconomic news after the crisis, as also found in news-regressions (see Galati et al. 2011, Autrup and Grothe, 2014, or Nautz and Strohsal, 2015).

\footnotetext{
${ }^{7}$ Note that the immediate aftermath of the Lehman brothers bankruptcy is thus excluded from both baseline and pre-crisis sample. This is necessary as the associated financial market turmoil severely distorted the information content of market based inflation expectations.

${ }^{8}$ Note that the response of short-term expectations to a unit macro news shock, on the other hand, is quantitatively almost identical in both sample periods. Corresponding IRFs are available upon request.
} 


\section{Additional Figures}

Figure 3 Impulse responses of inflation expectations to the macro news shock - pre-crisis period

b) long-term expectations

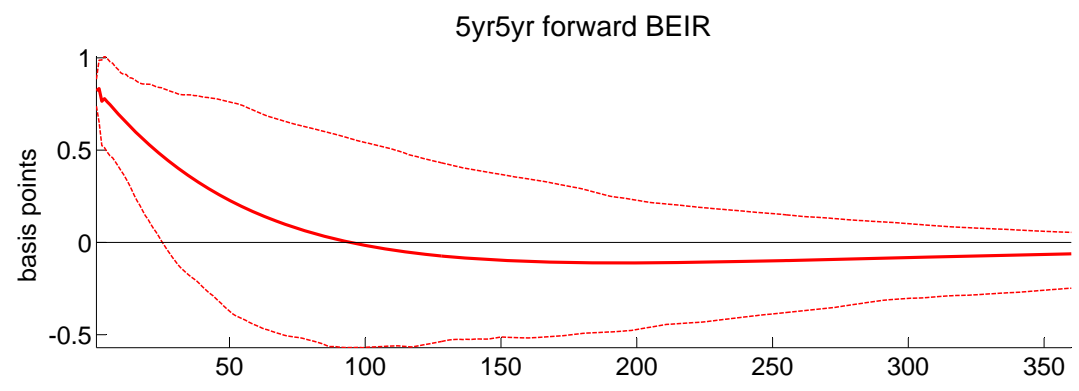

Note: The figure shows the estimated impulse responses, along with their 90 percent confidence bands, obtained using 500 bootstrap replications, of long-term inflation expectations to a unit macro news shock. The sample is $01 / 01 / 2004-08 / 31 / 2008$. 
Figure 4 Responses of long-term expectations from models with different short-term measures

a) two year BEI rate

5yr5yr forward BEIR

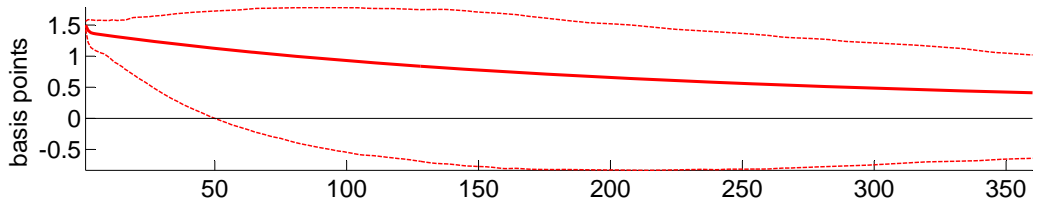

b) three year BEI rate (baseline)

5yr5yr forward BEIR

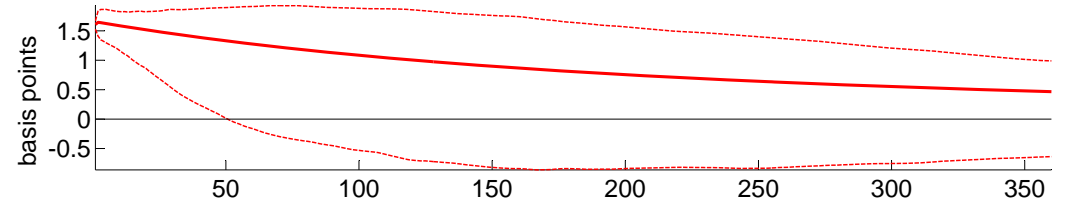

c) four year BEI rate

5yr5yr forward BEIR

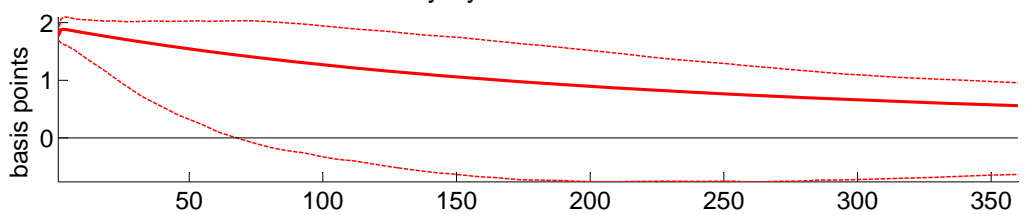

Note: The figure shows the estimated impulse responses, along with their 90 percent confidence bands, obtained using 500 bootstrap replications, of long-term inflation expectations to a unit macro news shock. The sample is $07 / 01 / 2009-08 / 26 / 2016$. The different responses come from models with different measures of short-term inflation expectation. Top: two year break-even inflation rate, middle: baseline, bottom: four year break-even inflation rate. 
Figure 5 Responses of long-term expectations from models with different expectations measures

a) different forward rate for long-term expectations

1yrgyr forward BEIR

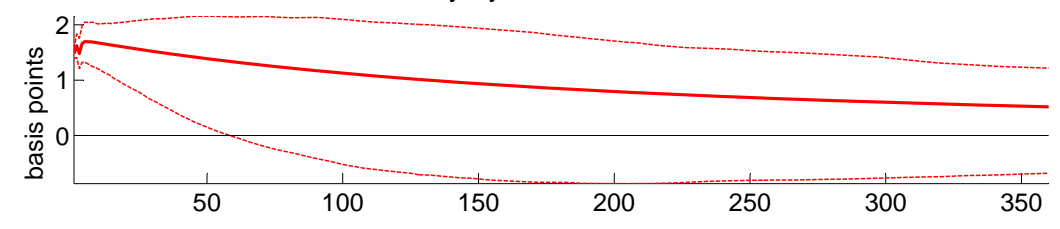

b) inflation swap rates

5yr5yr forward swap rate

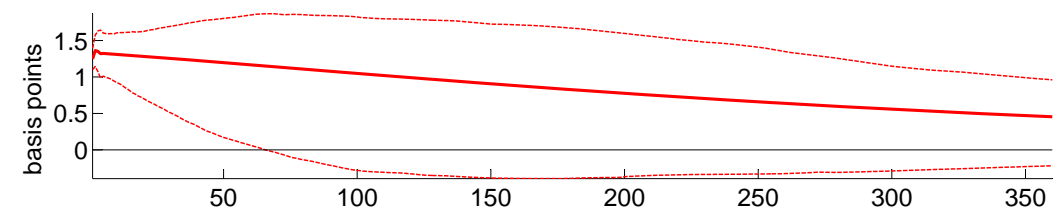

c) BEI rates adjusted with trading volume

5yr5yr forward BEIR - adjusted with volume

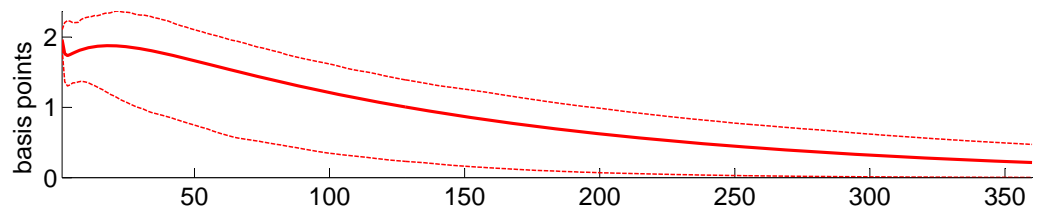

d) BEI rates adjusted with implied volatility

5yr5yr forward BEIR - adjusted with vix

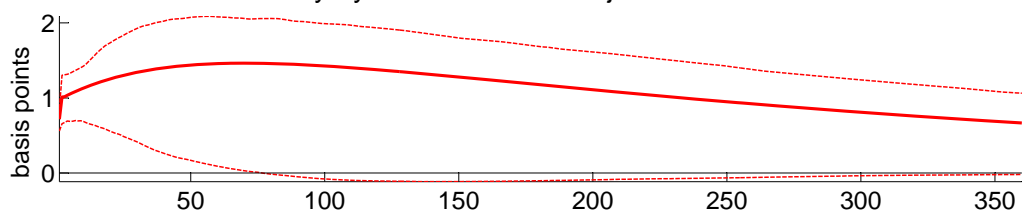

Note: The figure shows the estimated impulse responses, along with their 90 percent confidence bands, obtained using 500 bootstrap replications, of long-term inflation expectations from different model specification to a unit macro news shock. The sample is $07 / 01 / 2009-08 / 26 / 2016$. Top: one year nine year BEI rate as long-term measures, top middle: inflation swaps instead of BEI rates, bottom middle: BEI rates pre-filtered with trading volume, bottom: BEI rates pre-filtered with implied stock market volatility. 


\section{Additional Tables}

Table 5 Percentage contribution of macro news shock to variance of inflation expectations in

\begin{tabular}{c|cccccccc}
\multicolumn{1}{c}{ pre-crisis sample } \\
\hline \hline & \multicolumn{8}{c}{ Horizon in days } \\
Variable & 1 & 5 & 10 & 20 & 30 & 90 & 150 & 360 \\
\hline$\pi_{l}^{e}$ & 9 & 8 & 8 & 7 & 7 & 5 & 5 & 5 \\
\hline \hline
\end{tabular}

Note: The table shows forecast error variance decompositions of long-term inflation expectations from the baseline Proxy SVAR model specification estimated over a pre-crisis sample period (01/01/2004 08/31/2008). 


\section{Diskussionsbeiträge - Fachbereich Wirtschaftswissenschaft - Freie Universität Berlin Discussion Paper - School of Business and Economics - Freie Universität Berlin}

2017 erschienen:

2017/1 ARONSSON, Thomas und Ronnie SCHÖB

Habit Formation and the Pareto-Efficient Provision of Public Goods

Economics

2017/2 VOGT, Charlotte; Martin GERSCH und Cordelia GERTZ

Governance in integrierten, IT-unterstützten Versorgungskonzepten im Gesundheitswesen : eine Analyse aktueller sowie zukünftig möglicher Governancestrukturen und -mechanismen

Wirtschaftsinformatik

2017/3 VOGT, Charlotte; Martin GERSCH und Hanni KOCH

Geschäftsmodelle und Wertschöpfungsarchitekturen intersektoraler, IT-unterstützter Versorgungskonzepte im Gesundheitswesen Wirtschaftsinformatik

2017/4 DOMBI, Akos und Theocharis GRIGORIADIS

Ancestry, Diversity \& Finance : Evidence from Transition Economies Economics

2017/5 SCHREIBER, Sven

Weather Adjustment of Economic Output

Economics

2017/6 NACHTIGALL, Daniel

Prices versus Quantities: The Impact of Fracking on the Choice of Climate Policy Instruments in the Presence of OPEC

Economics

2017/7 STOCKHAUSEN, Maximilian

The Distribution of Economic Resources to Children in Germany Economics

2017/8 HETSCHKO, Clemens; Louisa von REUMONT und Ronnie SCHÖB Embedding as a Pitfall for Survey-Based Welfare Indicators: Evidence from an Experiment

Economics

2017/9 GAENTZSCH, Anja

Do Conditional Cash Transfers (CCT) Raise Educational Attainment? A Case Study of Juntos in Peru

Economics 
2017/10 BACH, Stefan; Martin BEZNOSKA und Viktor STEINER

An Integrated Micro Data Base for Tax Analysis in Germany Economics

2017/11 NEUGEBAUER, Martin; Felix WEISS

Does a Bachelor's Degree pay off? Labor Market Outcomes of Academic versus Vocational Education after Bologna

Economics 